\section{Sexualidad, experiencias corporales y género: un estudio etnográfico entre personas viviendo con VIH en el Área Metropolitana de Buenos Aires, Argentina}

\author{
Sexuality, bodily experiences, and gender: \\ an ethnographic study of persons living \\ with HIV in Greater Metropolitan \\ Buenos Aires, Argentina
}

Mabel Grimberg ${ }^{1}$

\section{Introducción}

Based on the results of an ethnographic study on daily experience with HIV in Greater Metropolitan Buenos Aires, Argentina, the article discusses behavioral approaches that reduce the sexuality of persons living with HIV to an issue of safety and protection. By articulating a social construction perspective and the notion of hegemony, the author proposes that sexuality can be understood as a process of individual and social construction shaped by power relations and social regulations. The analysis of the experiences of living with HIV in marginalized populations shows how chronic social inequality, violence, discrimination, and stigmatization generate particular characteristics of sexual issues. These social processes become driving forces that shape sexual experience as a field of danger, repression, and restriction rather than pleasure and exploration. Finally, daily confrontation with social metaphors places strain on gender relations, practices, and identities.

HIV; Acquired Immunodeficiency Syndrome; Sexuality; Gender Identity
Este trabajo forma parte de un proyecto de investigación sobre la experiencia de vivir con VIH, realizado en varias etapas desde 2001, apoyado por el Consejo Nacional de Investigaciones Científicas y Técnicas (CONICET) y la Universidad de Buenos Aires Ciencia y Tecnología (UBACyT); articula las categorías de construcción social y hegemonía con el propósito de contribuir al desarrollo de enfoques críticos relacionados con la problemática social del VIH/SIDA.

Desde finales de los ochenta las ciencias sociales han avanzado en la necesidad de considerar relacional y contextualmente la sexualidad, incluyendo las configuraciones de género, clase y étnicas en el análisis de las identificaciones, las relaciones y las prácticas sexuales 1,2,3. En este marco, nuestra investigación aborda la sexualidad como un proceso de construcción a la vez individual y social, que supone una trama de intercambios complejos modelados por relaciones de poder y dispositivos de regulación social.

A partir de los resultados de un estudio etnográfico en el Área Metropolitana de Buenos Aires, Argentina, este artículo discute enfoques de comportamiento que reducen la sexualidad de personas viviendo con VIH a un "problema de seguridad” y responsabilidad individual, aíslan las prácticas sexuales de las trayectorias y contextos de vida, naturalizando y desconociendo su carácter generizado y corporizado. Seguimos 
los relatos de mujeres y varones para argumentar que vivir con VIH es un proceso activo que confronta metáforas sociales ${ }^{4}$ de género. Entendemos este último como una construcción social e histórica de carácter relacional, configurada a partir de las significaciones y la simbolización cultural de las diferencias anatómicas entre varones y mujeres. Instituye una serie de asignaciones sociales que van más allá de lo biológico, a partir de las cuales se adjudican características, funciones, responsabilidades y derechos, es decir, "modos de ser" y "actuar" para unas y otros 5 , produciendo y reproduciendo relaciones de desigualdad y opresión social 6,7. Este abordaje es crítico de enfoques que muestran a la mujer sólo en el rol pasivo de la subordinación y el sufrimiento, o entienden el poder exclusivamente como dominio masculino, sin analizar las especificidades de los padecimientos que ambos géneros sufren cotidianamente, ni las iniciativas y las resistencias que realizan, especialmente las mujeres, confrontando construcciones de género hegemónicas.

Este trabajo argumenta que la experiencia de vivir con VIH pone al descubierto dimensiones de la subjetividad y contextos de vida marcados por múltiples procesos de desigualdad social y violencias, y conjuntos sociales sujetos a relaciones de subalternidad y continuas formas de estigmatización y discriminación social. En ese entramado de desigualdades y estigmatizaciones, la sexualidad se configura más como un dominio de peligro, restricción y represión, que de exploración y placer. Finalmente, que la confrontación cotidiana con metáforas sociales tensa relaciones, prácticas e identificaciones de género.

\section{Notas metodológicas}

Algunos datos de contexto, según fuentes oficiales en Argentina viven con VIH-SIDA aproximadamente 134.000 personas, un 50\% desconocería su condición. Se registran un total de 34.214 casos acumulados de SIDA a nivel nacional; el 76\% concentrados en el Área Metropolitana (33\% en la ciudad de Buenos Aires, $43 \%$ en el Gran Buenos Aires). El 50,4\% de los casos acumulados corresponde a transmisión sexual (heterosexual 32,5\% y por HSH 17,9\%), mientras que los correspondientes al uso de drogas por vía inyectable alcanzan un 32,1 \%. Los nuevos casos del año 2006 muestran un notorio aumento de la trasmisión por relaciones heterosexuales $62,9 \%$, HSH 13,9\%. La razón 2,4/1 hombres por mujer se mantiene estable en los últimos cinco años. Los casos notificados de infección por VIH son para todo el país 67.629 , contándose 1,5 hombres por mujer; desde el 2000 la principal vía de transmisión es la sexual con $82,5 \%$ (heterosexual $61,5 \%$ y $\mathrm{HSH}$ $21 \%$ ), usuarios de drogas inyectables $7 \%$ y transmisión vertical $3 \%{ }^{8}$.

Realizamos un estudio etnográfico que combina entrevistas en profundidad, observación con participación y análisis de narrativas biográficas. Las narrativas constituyen aquí una instancia privilegiada para analizar las interpretaciones y sentidos que los sujetos dan a sus experiencias de vida, ya que ellas permiten aprehender cómo los sujetos organizan, dan un orden y sentido de totalidad a acontecimientos vividos como fragmentarios; logran explicaciones y modos de comprensión de sí mismos que posibilitan reorientar trayectorias y relaciones sociales ${ }^{9}$.

Acorde con nuestro objetivo de indagar las desigualdades de género en contextos de la vida cotidiana, incluimos mujeres y varones con tres y más años de diagnóstico, en tratamientos ambulatorios en servicios públicos o de obras sociales. Realizamos nuestro trabajo de campo en dos hospitales públicos, una asociación de personas viviendo con VIH y organizaciones que ejecutan programas de prevención y atención, alcanzando un total de 52 personas viviendo con VIH. Combinamos dos estrategias: la primera, una redefinición de la estrategia etnográfica de trabajo con "informantes clave", en este caso integrantes de dichas instituciones, quienes nos contactaron con personas viviendo con VIH. La segunda, de trabajo con las redes de solidaridad (amigos y conocidos) con quienes nos relacionamos.

Para este trabajo, consideramos los datos de treinta y cuatro mujeres y varones autodefinidos como de orientación heterosexual, con antecedentes de uso de "drogas" por vía inyectable o con parejas con dichos antecedentes. En su mayor parte tenían entre 10 y 15 años de diagnóstico y entre 35 y 40 años de edad, con un mayor número de varones de más de 40 años y, de mujeres menores de 30 años. Las mujeres alcanzaban mayor nivel de escolaridad, algunas con estudios secundarios completos, menos con terciarios o universitarios incompletos o en curso; los varones mostraban disparidades, en un mayor número con estudios primarios completos o secundario incompleto.

Residen en barrios del sur de la ciudad de Buenos Aires y localidades del primer cordón de Gran Buenos Aires, caracterizados por problemas de infraestructura de servicios, vivienda, salud, etc. e históricas condiciones de empleo precario, desempleo, pobreza y violencias. Habitan viviendas en construcción, asentamientos, edificios (ilegalmente) ocupados, inquilinatos, pensiones u hoteles de baja renta, y un hogar para personas con VIH con problemas de trabajo 
y vivienda. Una parte significativa ha llegado al Área Metropolitana en distintas fases migratorias desde el interior y países vecinos (sobre todo Chile y Uruguay), otros han nacido y vivido en el área. Los de mayor tiempo diagnóstico pasaron por distintas experiencias y tipos de "terapias", grupos religiosos, técnicas orientales, grupos de autoayuda, encontrándose durante nuestro trabajo de campo en tratamientos antirretrovirales ambulatorios.

\section{Entre la "seguridad" y la "amenaza"}

Hasta mediados de los noventa los estudios sobre la sexualidad de las personas con VIH eran limitados y no sistemáticos. Si bien se sugirió que su escasa presencia podría vincularse a la asociación SIDA-muerte hasta las terapias antirretrovirales, cabría pensar en el peso de estereotipos estigmatizantes en los enfoques de los propios investigadores 10. En ese contexto, la preocupación por la "seguridad" en las prácticas sexuales, el "sexo seguro", llevó a incluir estos aspectos en estudios con orientaciones biomédicas y enfoques predominantemente individualistas.

Desde finales de los noventa, algunos estudios en Europa y Estados Unidos analizaron situaciones de interacción social e indagaron su asociación a "prácticas sexuales no protegidas". Esos trabajos mostraron que la frecuencia de dichas prácticas era mayor cuando el compañero sexual era VIH positivo 11,12,13; que para las mujeres resultaba más difícil negociar el uso de preservativos con una pareja VIH positiva o con compañeros ocasionales 14,15 , y que este uso era más consistente en los casos de nuevas "parejas regulares” 16,17. Más recientemente, otros estudios focalizaron el papel de la intimidad y el amor, encontrando que en "parejas regulares" las medidas de protección se experimentaban como interferencias 18, mientras que en una "relación ocasional" resultaban una manera de negar su situación 10,18. Con una visión amplia de la vida sexual como constituida en las interacciones con otros, varios investigadores propusieron estudios de largo plazo que permitieran dar cuenta de las múltiples maneras en que las personas van construyendo su "estatus como seropositivos" y redefiniendo su actividad sexual 2,3,10.

Si bien toda experiencia de enfermedad resulta una confrontación con las metáforas dominantes en una sociedad 4, elVIH/SIDA constituye un particular significante social. Su vinculación a prácticas "desviadas" y a conjuntos sociales negativamente valorados, actualizó y reforzó, categorías estigmatizantes y prácticas discriminatorias. El peso de estigmatizaciones sobre la sexualidad y al uso de "drogas", consolidaron su asociación al "sexo peligroso", las "sexualidades promiscuas", las “drogas” y a imágenes de "excesos" y "descontrol". En este marco debe entenderse un todavía vigente enfoque de la sexualidad de las personas con VIH como problema de seguridad, tanto en prácticas clínicas, como en estudios epidemiológicos y sociales, en los que el objetivo se limita a "medir" la "frecuencia" y "consistencia" de "las prácticas protegidas" según situaciones y tipos de compañeros sexuales, tal como lo muestran el uso homogeneizante de categorías dicotómicas: "relaciones ocasionalesparejas estables", parejas "discordantes-concordantes". Ese enfoque restringe la vida sexual a "actos arriesgados-peligrosos", promueve procesos de responsabilización individual e invisibiliza aspectos sustanciales de las trayectorias y los contextos de vida, en particular aquellos que combinan pobreza y precarización de la vida, procesos de dominación y discriminación étnica y racial, desigualdades de género y opresión sexual 2,3,19,20. No sólo limita la potencialidad de cualquier estrategia de salud pública, sino que, más allá de las voluntades individuales, contribuye a reforzar estereotipos, relaciones y condiciones de desigualdad y sufrimiento social.

El seguimiento de las trayectorias de vida de los sujetos de estudio da cuenta de historias migratorias con experiencias de discriminación, desocupación y pobreza. Sus relatos también revelan trayectorias de uso de "drogas" o parejas con estas trayectorias, empleos precarios, actividades ilegales, experiencias carcelarias y de violencias de diverso tipo. Varios de ellos pasaron por internaciones y episodios críticos, así como debieron afrontar la muerte de parejas, hijos o amigos.

Trabajamos en primer término algunos ejes de organización de esta experiencia en relación con la sexualidad, para luego distinguir ciertas especificidades de género.

Una primera cuestión a destacar es que a diferencia de las imágenes de "sexo peligroso", "excesos" y "descontrol", contenidas en discursos de "protección sexual", este estudio puso al descubierto procesos prolongados de "parálisis sexual", culpabilizaciones y temores "a contagiar" y a "ser reinfectado". Tanto varones como mujeres experimentaron "falta de deseo" y "placer", así como situaciones "dolorosas" de "rechazo", discriminación y violencia en su práctica sexual. Distinguiéndose de discursos médicos o de programas sociales, relacionaron estos padecimientos a procesos más generales de "parálisis" y “aislamiento" en otros aspectos de su vida, como el trabajo, las relaciones familiares, los amigos, los vecinos, etc. 
El caso de Rita permite aproximarse a estas experiencias. Con antecedentes de uso de "drogas”, había conseguido trabajo en un pequeño taller de costura, convivía con una pareja reciente no usuaria, uno de sus amigos había contraído el VIH y pasado por diversos episodios de internación, conocía otros usuarios o ex usuarios en la misma situación, y, como afirmó, "llegó" al diagnóstico cuando se sintió parte de "un grupo de riesgo". Rita describió un prolongado período de "parálisis sexual" y aislamiento general. La pérdida de su empleo y la incomunicación familiar caracterizó un período dominado por "temores" y "culpas": "después del último resultado... yo entré en una parálisis sexual, ..., no seguí viviendo con J.... estaba completamente paralizada, ...me echaron del trabajo, no podía comunicarme con mi familia...estaba encerrada... tenía miedo de contagiar, bueno toda esta cuestión que te decía el médico que me atendía, un grupo de gente que se reunía en el hospital... tenés que cuidarte y cuidar al otro y durante mucho tiempo estuve con miedo de contagiar... mi relación con J. siguió un poco más tiempo y terminó..." (Rita [nombres ficticios], 36 años de edad, pareja no conviviente, 10 años de diagnóstico).

Como surge de distintos relatos, estas experiencias no se circunscriben al período posterior al diagnóstico, se prolongan en el tiempo en diversos tipos de padecimientos cotidianos: “... fue como parar y dar de nuevo... no te hablo del shock..., ni... de crisis, ... toda tu vida te viene a la cabeza, ... luego ... comenzás a aceptar, a asentarte y vas viendo como vivís el día, yo pude dejar de consumir, reestablecí ciertas relaciones y después de 14 años te digo que mi vida sexual no es igual ... he pasado por momentos de rechazo ... que al conversar de mi situación me hicieran a un lado... Estás ahí en el medio tironeado... enfrentado al peligro, si no te cuidás... y entonces a veces ni tengo ganas..." (Jorge, 41 años de edad, pareja no conviviente, 14 años de diagnóstico.)

“...No puedo controlar, no siento, es como que yo siento que ahí sí... el contagio bueno a través del sexo... me mutiló..." (María, 36 años de edad, pareja conviviente, 8 años de diagnóstico).

Debe reconocerse que contraer el VIH no es un episodio puntual en la vida de alguien, es su vida misma 5. Por eso, vivir con VIH implica experimentar un complejo variable de incertidumbres y padecimientos diarios, en una confrontación cotidiana con estigmas sociales y, al mismo tiempo, afrontar un conjunto de coerciones de "normalización", entre otras cumplir un tratamiento médico, reorganizar la vida cotidiana y su mundo de relaciones. Es en el marco de esas incertidumbres y del entramado de estigmatizaciones y coerciones sociales y médicas, cómo la sexualidad se torna una amenaza para otros y para sí, configurándose más como un dominio del peligro, la restricción y la represión que de exploración y placer.

En esa configuración es posible identificar ciertos diferenciales de género entendidos como los matices, los énfasis, las preocupaciones, los recursos, en otros términos las significaciones puestas en juego en los modos de experimentar de varones y mujeres. Estos diferenciales se sustentan en una construcción hegemónica de la sexualidad que, en nuestra sociedad, equipara sexualidad a heterosexualidad reproductiva, establece los límites entre sexualidad "normal" y "anormal", instituyendo prácticas "naturales" y "no naturales". Sostiene una representación dicotómica que separa y opone "acto físico" y "amor"; confiere el deseo, el placer y la iniciativa sexual al varón, mientras coloca a la mujer en el lugar de la entrega o la concesión, constituyendo el "amor" en requisito y justificación de su práctica sexual. Esta escisión produce y reproduce una tipología clasificatoria sociomoral que diferencia entre "buenas" y "malas" mujeres - "madres", "amigas", "locas", "putas" etc. 5,7.

Centraré, a continuación, en el momento posterior al diagnóstico en el caso de parejas porque a mi criterio, permite entender cómo las construcciones de género instituyen dicotomías de valores, normativas y prácticas, simultáneamente opuestas y complementarias entre varones y mujeres, "generando" relaciones y situaciones de desigualdad, así como modos y sentidos de sufrimiento en unos y otras.

Para algunos de los varones en pareja el período posterior al diagnóstico implicó una dinámica de ocultamientos y revelaciones, "culpas" y "abandonos", en algunos casos instalando la sospecha o la "confirmación" de "infidelidades", como el caso de Víctor, con cuatro años de casado y salidas semanales con un grupo de amigos: "yo era de salir a divertirme con mi barra... una o dos veces por semana... eran pequeñas infidelidades de vez en cuando...por un amigo me hice el test y después empezó toda la locura... bueno de toda una película que hizo... me acusó...eh bueno de andar con otras... hubo peleas... no quiso saber nada, me dejó... nunca quiso escucharme... por suerte ella estaba bien que si no... me mato" (Víctor, 44 años, sin pareja, 16 años de diagnóstico).

En otros, haciendo visibles pasados o presentes de uso de "drogas".

“...Recién salía de la cana [prisión] y conocí a una chica... más joven... y bueno nos fuimos a vivir juntos... no le dije nada, ni que consumía, ni que había estado preso... era otra vida para mi, al tiempo empecé a tener problemas, tuve una neumonía... una infección en los riñones... no se 
sabía, pasaron como dos años... con el diagnóstico saltó todo, S. se persiguió... se peleó y... se fue" (Jorge).

A diferencia, un número significativo de mujeres recién conocieron el status VIH-positivo de sus parejas a partir de su propio diagnóstico. En estos casos, ellas describieron una amplia gama de experiencias de "dolor", "bronca", "resentimiento", enfrentamientos verbales y momentos de violencia. Para algunas como Elena, una joven chilena conviviendo en pareja desde los 16 años, implicó enfrentarse a una situación de "infidelidad", experimentar rechazo sexual y pérdida de erotismo: “...fue tremendo, él no sabía como decírmelo, porque además me tenía que admitir que había andado con otras... que me había contagiado... eh bueno después yo tenía tanta bronca que no lo dejaba ni acercarse, durante muchísimo tiempo no podía tocarlo, ni sentir que el me tocara, me crispaba..." (Elena, 24 años, pareja conviviente, 4 años de diagnóstico).

Para otras, la vivencia de "traición" de sus parejas se articuló a un pasado o un presente de uso de "drogas" oculto, como el caso de María, una mujer que tras cuatro años casada, debió enfrentar un diagnóstico durante sus análisis prenatales. Posteriormente, se enteró que su marido llevaba un año de diagnóstico y había seguido utilizando "drogas" inyectables.

“....Fue terrible... primero saber que estaba infectada... en medio de los análisis, yo tenía problemas..., había perdido uno, bueno esta parecía que podía ir... dos años antes no tenía nada... hasta que él me dijo que hacía un año que el test... había salido positivo, sentí un total rechazo y todavía lo siento... no puedo controlar, no siento, es como que yo siento que ahí sí... el contagio bueno a través del sexo... me mutiló..." (María).

Una mirada de conjunto a los casos analizados permite advertir la operatoria de dicotomías de opuestos y complementarios de género: deseo, placer, iniciativa (sexual o en el consumo de sustancias) en el varón/entrega, concesión, confianza en la mujer. Esta operatoria refuerza tanto la visibilidad de los varones como su responsabilización en contraer y transmitir el VIH, aquí "culpa", "rechazo" y "abandono" constituyen los principales sentidos del sufrimiento. Al mismo tiempo, tiende a invisibilizar a las "buenas" mujeres en el lugar pasivo de la entrega y el amor, como "esposas de" o "víctimas de" la "traición" sexual o el consumo de "drogas" de otro; "traición”, "bronca”, "enojo", "resentimiento" conforman los sentidos del sufrimiento entre ellas.

\section{Cuerpos y confrontaciones de género}

Sustancial a los enfoques de comportamiento de "seguridad sexual" para personas viviendo con VIH es su notoria descorporización de las relaciones y prácticas sexuales. Nos interesa aquí centrarnos en ciertas modalidades narrativas y sentidos de género que permiten entender la sexualidad como experiencia corporal. El cuerpo ha cobrado una fuerte presencia en la antropología y la teoría social contemporánea. Parte de este interés se relaciona con su creciente visibilidad en las sociedades occidentales y, en particular, con cambios sociales que lo sitúan como centro de representaciones y prácticas sociales 21 . Desde finales de los ochenta, la producción antropológica ha abordado el cuerpo como un activo, y fluido, proceso material y simbólico, de carácter individual, social y político, objeto de disciplina y control y, al mismo tiempo, base de resistencias y reconstituciones identitarias 22,23 . Un aporte ha sido la profundización de su desnaturalización, reintegrando su historicidad e incluyendo la sexualidad y el género en el marco de una reflexión teórica sobre la naturaleza, la cultura y la biología 24. Cuestionando el dualismo positivista cartesiano mente-cuerpo, contribuciones recientes propusieron entender el cuerpo no como objeto, sino como agente activo de toda experiencia de vida, como "base existencial del sujeto y la cultura” 25,26. En esta perspectiva resulta central la noción de incorporación ("embodiment") que recupera la experiencia de la percepción y los modos de presencia y compromiso en el mundo, para plantear que la vida social está enraizada en el cuerpo, y que es a través y por medio de éste, es decir, de experiencias corporales, como se constituye la vida social y los sujetos. En este sentido es posible hablar de corporización generizada de la experiencia cotidiana y recuperar las dimensiones de la percepción, las emociones y los sentimientos, además de los aspectos cognitivos y representacionales.

Siguiendo esos aportes, me centro en dos casos que permiten dar cuenta de esta corporización generizada: nos ocupamos primero de la "protección" en nuevas relaciones, para concentrarnos luego en las eróticas corporales.

\section{Primer caso}

La sexualidad se configura en un contexto social que orienta la experiencia y la expresión del deseo, las emociones y las prácticas corporales 27. Como veremos a continuación, afrontar nuevas 
relaciones resulta una experiencia en que verbalización, corporalidad y poder se articulan en un estructura inversa para varones y mujeres.

El análisis de narraciones muestra una notoria desigualdad de recursos, mientras que para una gran parte de los varones revelar su status positivo en una nueva relación resultaba innecesario, en tanto pudieran "manejar"/ "controlar" el uso de un preservativo; las mujeres "debían”, es decir se veían obligadas a comunicar su situación para asegurar "protección" en sus relaciones sexuales. Tres relatos nos permiten dar cuenta del carácter y los sentidos de esta desigualdad de recursos y su impacto en la experiencia.

“...Yo después de una crisis fuertísima, y momentos muy jodidos, que no podía ni pensar en una mujer... bueno me sentí mejor... y comencé a salir..., yo soy bastante fiestero, la verdad, me di cuenta que no hay tanto problema como yo me hacía, no es bueno andar por ahí contando que me pasa, que soy, si saben por otro lado bien, yo no tengo porqué decir nada, con ponerme bien el preservativo ya está... si me enamoro ahí veré..." (Néstor, 34 años de edad, sin pareja, 9 años de diagnóstico).

“...Me encontré siempre en varias situaciones difíciles... la mayoría tiende a no usar preservativos... me colocan en la cuestión de si blanquear o no,... las veces que hablé abiertamente, no sabes, ¿para quéi un tipo que me encantaba se aterrorizó y ahí quedó todo..." (Ana, 41 años de edad, sin pareja, 12 años de diagnóstico).

“...Hace tiempo que no tengo relaciones sexuales, conozco siempre a alguien pero no sé... me es difícil decirle, me ha pasado de conversar y plantear el cuidado, pero en el momento el tipo no quiere... tuve una situación violenta... horrible" (Ema, 27 años de edad, sin pareja, 5 años de diagnóstico).

\section{Segundo caso}

El segundo caso permite mostrar que las construcciones de género articulan eróticas corporales desiguales en mujeres y en varones. Los imperativos de una construcción hegemónica de la sexualidad femenina que hace eje en una erótica corporal, para otros ponen en crisis aspectos sustanciales de sus identificaciones de género en las mujeres viviendo con VIH. Retomamos parte de la narración de María: “...siento como que... desde lo femenino... algo en mí se descalificó como mujer ¿no? porque yo antes era... de ropitas usar.. más seductora... tenía... otra forma de ser con los hombres... eso quedó completamente dormido... me cambió el cuerpo, se me ha deformado por la medicación... tengo más grasas en las caderas siento que no puedo atraer a nadie...”.
La vida cotidiana con VIH resulta, entonces, una permanente confrontación con las construcciones sociales hegemónicas del cuerpo femenino como objeto erótico y sus modelos "estéticos". Imágenes no deseadas de sí mismas, temores a no resultar "atractivas", experiencias de rechazo fueron reiteradamente descritas. Tal como lo expresó Julia (25 años de edad, sin pareja, 4 años de diagnóstico): “...no pude seguir con mi novio... el miedo de él, el rechazo... y un poco que yo no podía despertar... pasión en nadie, estaba destruida... ¿cómo se puede mantener el deseo?... no sé, yo a veces pienso que nadie puede sentir algún deseo por mí...".

Otro aspecto de esta erótica se relaciona con el papel adjudicado a la maternidad como un significante del rol y la "identidad" femenina. En algunos casos como en el de Tina, tener y perder un hijo confirmó a su sexualidad en agente de contagio y a su cuerpo en objeto vacío de sentido. Una "cáscara vacía”, como ella relató: “...me quedé embarazada un poco más de dos años después del diagnóstico, la discusión con los médicos fue si la tenía o no... la nena nació positiva, pensé que podía ir todo bien, pero no... fue desesperante... murió al año... me quería matar... rechazaba todo, a él, a mi cuerpo, era como si fuera una cáscara vacía, sin sentido..." (Tina, 32 años de edad, pareja no conviviente, 6 años de diagnóstico).

Para los varones la erótica corporal reviste otras aristas y significaciones. Como he señalado en otro trabajo vivir con VIH supone una experiencia de fragilidad corporal que impugna la construcción de las masculinidades ${ }^{6}$. En efecto, la asimilación de la "masculinidad" a una sexualidad permanentemente activa, su vinculación a imágenes de fuerza física, iniciativa y control se tensa en las sensaciones de debilidad, falta de fuerza o cansancio y en los temores y angustias cotidianas.

Para algunos las asociaciones entre "sexo peligroso" y "fragilidad corporal" supusieron procesos de sufrimiento emocional y "rupturas" de núcleos básicos de sus identificaciones masculinas: “...yo sentía y todavía siento una especie de vacío... difícil de describir... es una sensación... especialmente si uno se sentía Superman... pero lo peor es que estás siempre con temores... es difícil sentirse un hombre... yo me quebré y me llevó mucho poner luego las piezas juntas otra vez..." (Diego, 44 años de edad, sin pareja, 12 años de diagnóstico).

Otros experimentaron estas "rupturas" como un "desorden interno", o como una "pérdida de iniciativa y control” sexual y por tanto social: “... no tengo energía, ni fuerza, el cuerpo no responde... he perdido la manera de abrazar y de estar con una mujer... yo no puedo asumir ningún com- 
promiso... todavía no he encontrado la manera de hacer una vida normal..." (Daniel, 33 años de edad, sin pareja, 5 años de diagnóstico).

En algunos de los participantes esta experiencia de fragilidad ha significado un cambio de roles y una variedad de sentimientos, tanto de frustración, como de una nueva y no deseada situación de dependencia hacia los otros. Retomando el relato de Ricardo (34 años de edad, pareja conviviente, 6 años de diagnóstico): “...yo cambié... de ser un tipo en el que mi familia se apoyaba... soy un tipo dependiente del cuidado de mi mujer, del cuidado médico, ...necesito de otros... también los otros se cuidan de mí aunque no lo digan... te imaginas que hay veces que no sé con quien estoy si con mi mujer o con mi vieja... tengo mucha dificultad sexual o no tengo ganas... me canso, que sé yo... me cuesta llegar...".

Un último aspecto a tener en cuenta, el VIH/ SIDA comporta una crisis en la que la subjetividad requiere ser redefinida desde renovados límites 28. Para algunos de los participantes de este estudio ha sido posible un trabajo de reconstrucción y un "reaprendizaje". Tanto mujeres como varones describieron sus "esfuerzos" por rearmar su vida sexual como un "duro aprendizaje de vida”, en palabras de una de las mujeres. Para Susana este "aprendizaje" requirió "conocer" o "inventar" nuevas modalidades de relación sexual para "una vida normal”: “...este ha sido un duro aprendizaje de vida, con sensibilidad y con inteligencia, porque el amor no es sólo sexo, ni sexo es sólo pasión descontrolada... hay que aprender a disfrutar de todo el cuerpo y con todo el cuerpo... tener una vida normal es poder conocer o inventar,... tampoco hay recetas ¿no?...” (Susana, 32 años de edad, pareja conviviente, 10 años de diagnóstico).

Los relatos de los varones hicieron énfasis en estar "creando" otros repertorios, estar comprometidos con promover la iniciativa sexual de sus parejas o en compartir el control durante la relación. En la mayor parte de estos casos integran asociaciones que realizan distintos programas sociales. Como indicó Rodolfo, "activista" de una asociación del Gran Buenos Aires en pareja con una mujer VIH positiva: “...nosotros pensamos que el sexo no es una rutina, tratamos de crear nuestra propia manera, no sé, tenemos más variedad de cosas para hacer, es todo más abierto... trato de compartir, de no ser el controlador... dar más atención en los besos y las caricias... hemos ido a talleres y yo estoy dando un taller en el que insistimos en tratar de ver que el sexo es creatividad..." (Rodolfo, 39 años de edad, pareja conviviente, 14 años de diagnóstico).

\section{Reflexiones finales}

El recorrido temático e interpretativo presentado permite plantear una serie de reflexiones para el campo de las ciencias sociales y la salud pública. Este trabajo se propuso discutir enfoques de comportamiento que reducen la sexualidad de personas viviendo con VIH a un "problema de seguridad” y responsabilidad de protección, aíslan las prácticas sexuales de las trayectorias y contextos de vida, naturalizando y desconociendo su carácter generizado y corporificado.

Los resultados presentados muestran que contraer el VIH no es un episodio puntual en la vida de un sujeto, es un proceso individual y social, que permea la vida misma. En ese marco, la frase vivir con VIH resulta paradigmática, en tanto no sólo subraya la posibilidad efectiva de la vida, sino, al mismo tiempo, descubre su carácter de experiencia cotidiana como espacio en el que se entretejen relaciones y compromisos sociales, se refuerzan y se transforman procesos identitarios, se reproducen y se resisten construcciones coercitivas.

El análisis de esa experiencia revela dimensiones de la subjetividad y contextos de vida marcados por múltiples desigualdades y violencias, y conjuntos sociales sujetos a relaciones de subalternidad y continuas formas de discriminación social. Permite así visibilizar conjuntos y sujetos, prácticas, valores, normativas, procesos emocionales y modos de sufrimiento social diariamente ocultos tras estigmatizaciones y responsabilizaciones individuales. Contribuye al mismo tiempo, no sólo a una mayor comprensión de las problemáticas que día a día afrontan las personas viviendo con VIH, sino al cuestionamiento de prácticas homogeneizadoras y estereotipos generalizadores que refuerzan las bases de dichas desigualdades.

Como mostramos aquí, ir más allá del problema de la "seguridad" y la medición de la frecuencia y consistencia de "prácticas sexuales protegidas”, para priorizar la consideración de las trayectorias y los contextos de interacción social, posibilita aproximarse al entramado de desigualdades, estigmatizaciones y coerciones por el cual la sexualidad de las personas con VIH se configura en una fuerte tensión entre el peligro y el placer, mientras sus prácticas sexuales se tornan en "amenaza” para sí y para otros. De ahí que nuestros resultados señalen a la sexualidad más como un dominio del peligro, restricción y represión, que de exploración y placer.

Sin embargo, tal como surge de nuestro estudio, en un contexto en que la subjetividad requiere ser redefinida desde renovados límites, vivir con VIH ha implicado cambios relevantes, 
tanto la "parálisis sexual" como el "aprendizaje" de "formas creativas". Seguir este proceso permite dar cuenta de las múltiples maneras en que las personas van construyendo su vida como seropositivos y redefiniendo su actividad sexual; destaca al mismo tiempo, que esa vida es una activa construcción que confronta diariamente metáforas sociales, tensando relaciones, prácticas e identificaciones de género.

Los casos de análisis - el momento posterior al diagnóstico en parejas, las prácticas ante nuevas relaciones y las eróticas corporales - muestran cómo una perspectiva relacional de género permite identificar ciertos diferenciales, entendidos como los matices, énfasis, preocupaciones, recursos, en otros términos como significaciones puestas en juego en la experiencia. Posibilita aprehender cómo las construcciones de género instituyen dicotomías de valores, normativas, y prácticas, simultáneamente opuestas y complementarias entre varones y mujeres, "generando" relaciones y situaciones de desigualdad, modos y sentidos de sufrimiento en unos y otras.

Esas construcciones no sólo imponen condiciones de vulnerabilidad diferencial, sino posibilidades y límites también desiguales en los recursos y la construcción de estrategias de "normalización”. Parte de estos límites, es la confrontación de estereotipos sociales que asignan a las "buenas mujeres" un rol pasivo de "pareja de" o "víctima de" o las descalifican en términos de un cuerpo erótico para otros o un cuerpo para la maternidad. En los varones esos límites descubren una profunda crisis de las masculinidades, revelando la fragilidad corporal como una falta de control y esta falta, como desorden de la propia estructura de la masculinidad.

Tal como lo muestran estudios socioantropológicos y nuestros resultados, abordar la vida con VIH y en este marco la sexualidad, abre un desafiante camino en la construcción de perspectivas y herramientas de comprensión y acción. Ellos reafirman que la "protección" no depende sólo de recursos técnicos; el acceso y posibilidad de apropiación de esos recursos son parte de un proceso social complejo en el que pesan los modos, las condiciones y las trayectorias de vida de los sujetos y las historias sociales de los conjuntos involucrados. En esta perspectiva, la contextualización de acontecimientos, prácticas y trayectorias, el papel de lo simbólico, el trabajo con la diversidad de significaciones según conjuntos sociales, género, edad, etc., la conformación del campo de relaciones sociales (redes de amistad, parentesco, vecindad, etc.) y su incidencia en la experiencia de vivir con VIH constituyen parte sustancial de los aportes posibles de las ciencias sociales al campo de la salud pública.

\section{Resumen}

A partir de los resultados de un estudio etnográfico sobre la experiencia cotidiana de vivir con VIH en el Área Metropolitana de Buenos Aires, Argentina, este artículo discute enfoques de comportamiento que reducen la sexualidad de las personas viviendo con VIH a un problema de seguridad y protección. Combina las categorías de construcción social y hegemonía para abordar la sexualidad como un proceso de construcción a la vez individual y social, que supone intercambios complejos modelados por relaciones de poder y dispositivos de regulación social. Argumento que la experiencia de vivir con VIH pone al descubierto dimensiones de la subjetividad y contextos de vida atravesados por desigual- dades sociales y violencias, y conjuntos sociales sujetos a relaciones históricas de subalternidad y continuas formas de estigmatización y discriminación social. En este entramado de desigualdades y estigmatizaciones, la sexualidad se configura más como dominio de peligro, restricción y represión, que de exploración y placer. Finalmente, que la confrontación cotidiana con metáforas sociales tensa relaciones, prácticas e identificaciones de género.

VIH; Síndrome de Inmunodeficiencia Adquirida; Sexualidad; Identidad de Género 


\section{Referencias}

1. Weeks J. The invention of sexuality In: Heasley R, Crane C, editors. Sexual lives: a reader in the theories and realities of human sexualities. New York: McGraw-Hill; 2002. p. 39-49.

2. Parker R, Di Mauro D, Filiano B, Garcia J, MunozLaboy M, Sember R. Global transformations and intimate relations in the 21 st century: social science research on sexuality and the emergence of sexual health and sexual rights frameworks. Annu Rev Sex Res 2004; 15:362-99.

3. Boyce P, Lee MHS, Jenkins C, Mohamed S, Overs S, Paiva V, et al. Putting sexuality (back) into HIV/ AIDS: Issues, theory and practice Glob Pub Health 2007; 2:1-34.

4. Frankenberg R. Risk: anthropological and epidemiological narratives. In: Lindenbaum S, Lock M, editors. Knowledge, power and practice. Berkeley/ Los Angeles: University of California Press; 1993. p. 219-42.

5. Grimberg M. Narrativas del cuerpo. Experiencia cotidiana y género en personas que viven con VIH. Cuadernos de Antropología Social 2003; 17:79-100.

6. Scott J. Gender and the politics of history. New York: Columbia University Press; 1999.

7. Grimberg M. Estigmatización y discriminación social relacionada al VIH en países de América Latina: sexualidad y uso de drogas en jóvenes en contextos de precarización social urbana. In: Estigma y discriminación por el VIH/SIDA: un enfoque antropológico. París: División de Políticas Culturales y Diálogo Intercultural, Organización de las Naciones Unidas para la Educación, la Ciencia y la Cultura; 2005. p. 11-22. (Estudios e Informes, Serie Especial, 20).

8. Ministerio de Salud y Ambiente de la Nación. Boletín sobre VIH/Sida en la Argentina 2007; Año XII, $\mathrm{n}^{\circ} .25$.

9. Ricoeur P. Sí mismo como otro. Madrid: Siglo XXI; 1996.

10. Schiltz MA, Sanford T. HIV-positive people, risk and sexual behaviour. Soc Sci Med 2000; 50:1571-88.

11. Stall R, Ekstrand M, Pollak M, McKusick L, Coates L. Relapse from safer sex: the next challenge for AIDS prevention efforts. AIDS 1990; 3:1181-7.

12. Green G. Sex, love and seropositivity: balancing the risks. In: Aggleton P, Davies P, Hart G, editors. Safety, sexuality and risk. London: Taylor and Francis; 1995. p. 144-8.
13. Marks G, Bingman C, Duval T. Negative affect and unsafe sex in HIV-positive men. AIDS Behav 1998; 2:89-99.

14. Sherr L, Hankins C, Bennett L. editors. AIDS as a gender issue: psychosocial perspectives. London: Taylor and Francis; 1996.

15. De Vicenzi I, Jadand C, Couturier E, Brunet J-B, Gallais H, Gastaut J-A, et al. Pregnancy and contraception in a French cohort of HIV-infected women. AIDS 1997; 11:333-8.

16. Hankins C, Gendron S, Tran T, Lamping D. Sexuality in Montreal women living with HIV. AIDS Care 1997; 9:261-71.

17. Green G. Stigma and social relationships of people with HIV: does gender make a difference? In: Sherr L, Hankins C, Bennett L, editors. AIDS as a gender issue: psychosocial perspectives. London: Taylor and Francis; 1996. p. 46-63.

18. Rhodes T, Cusick L. Love and intimacy in relationship risk management: HIV positive people and their partners. Sociol Health Illn 2000; 22:1-26.

19. Farmer P. Pathologies of power: health, human rights, and the new war on the poor. Berkeley: University of California Press; 2003. (California Series in Public Anthropology, 4).

20. Singer M. The political economy of AIDS. Amityville: Baywood Publishing Co; 1997.

21. Martin E. The end of the body? Am Ethnol 1992; 19:121-40.

22. Scheper-Hughes N, Lock M. The mindful body: a prolegomenon to future work in Medical Anthropology. Med Anthropol Q 1987; 1:6-41.

23. Lock M, Kaufert P. Pragmatic women and body politics. New York: Cambridge University Press; 1998.

24. Haraway D. Simians, cyborgs and women: the reinvention of nature. New York: Routledge; 1991.

25. Csordas T, editor. Embodiment and experience: the existential ground of culture and self. New York: Cambridge University Press; 1994.

26. Good B. Medicina, racionalidad y experiencia: una perspectiva antropológica. Barcelona: Bellaterra Ediciones; 2003.

27. Heilborn HL. Entre as tramas da sexualidade brasileira. Estudos Feministas 2006; 14:43-59.

28. Crawford R. Boundaries of the self and the unhealthy other: reflections on health, culture and AIDS. Soc Sci Med 1994; 38:1347-65.

Recibido el 07/Ene/2008

Versión final presentada el 01/Abr/2008

Aprobado el 10/Jun/2008 